\title{
Development of Pore-Free Ti-Si-C MAX/AI-Si Composite Materials Manufactured by Squeeze Casting Infiltration
}

\author{
Anna Dmitruk, Krzysztof Naplocha, Andrzej Żak, Agata Strojny-Nędza, Hajo Dieringa, and KarlUIrich Kainer
}

(Submitted July 1, 2019; published online October 16, 2019)

\begin{abstract}
Open-porous MAX phase skeletons from $\mathrm{Ti}_{3} \mathrm{SiC}_{2}$ were manufactured by Microwave-Assisted Self-propagating High-temperature Synthesis (MASHS) and subsequently subjected to squeeze casting infiltration with an Al-Si lightweight casting alloy (EN AC-44200). This alloy was chosen due to its high flowability, corrosion resistance and good machinability. The manufactured composites, together with a reference sample of the original alloy, underwent testing of thermal properties, including thermal conductivity and diffusivity, specific heat and thermal expansion in the temperature range $50-500{ }^{\circ} \mathrm{C}$, which corresponds to the expected working temperatures of the material. The fabricated $\mathrm{AISi} / \mathrm{Ti}_{3} \mathrm{SiC}_{2}$ composites have significantly increased thermal stability, with coefficients of thermal expansion (approximately 10$11 \times 10^{-6}{ }^{\circ} \mathrm{C}^{-1}$ ) half that of the original alloy. As regards mechanical properties, the instrumental Young's modulus and Vickers hardness of the composite materials are 170.8 and $8.5 \mathrm{GPa}$, respectively. Moreover, the microstructure and phase composition, structural defects and potential impacts between constituents of the manufactured composites were characterized using SEM, TEM and STEM microscopy and EDS and XRD analysis.
\end{abstract}

Keywords advanced characterization, casting and solidification, composites, MAX phases, metallic matrix

\section{Introduction}

Titanium silicon carbide $\left(\mathrm{Ti}_{3} \mathrm{SiC}_{2}\right)$ is composed of $\mathrm{Si}$ atoms separated from each other by three Ti layers that accumulate $\mathrm{C}$ atoms around them (Ref 1). The interesting properties of $\mathrm{Ti}_{3} \mathrm{SiC}_{2}$ arise precisely from its crystal structure, in which metallic, covalent and ionic bonds are present. Like metals, it possesses high thermal conductivity $\left(34 \mathrm{~W} \mathrm{~m}^{-1} \mathrm{C}^{-1}\right)$ and electrical conductivity $\left(4.5 \times 10^{6} \mathrm{~S} / \mathrm{m}\right)$, good machinability with conventional tools, high resistance to crack propagation, and outstanding resistance to varying ambient operating temperatures (Ref 2). Like ceramics, it is characterized by high mechanical strength at elevated temperatures, a low coefficient of thermal expansion-resulting in increased dimensional stability of machine parts made from it-a high melting point, good corrosion and oxidation resistance, a high modulus of

Anna Dmitruk and Krzysztof Naplocha, Department of Foundry, Polymers and Automation, Faculty of Mechanical Engineering, Wrocław University of Science and Technology, 5 Łukasiewicza St., 50-371 Wrocław, Poland; Andrzej Żak, Department of Material Science, Welding and Strength of Materials, Faculty of Mechanical Engineering, Wrocław University of Science and Technology, 5 Łukasiewicza St., 50371 Wrocław, Poland; Agata Strojny-Nędza, Institute of Electronic Materials Technology, 133 Wólczyńska St., 01-919 Warsaw, Poland; and Hajo Dieringa and Karl Ulrich Kainer, Helmholtz Zentrum Geesthacht, Zentrum für Material- und Küstenforschung, MagIC Magnesium Innovation Centre, Max-Planck-Straße 1, 21502 Geesthacht, Germany. Contact e-mails: anna.dmitruk@pwr.edu.pl, krzysztof.naplocha@pwr.edu.pl, andrzej.zak@pwr.edu.pl, agata.strojny@itme.edu.pl,hajo.dieringa@hzg.de, and karl.kainer@hzg.de. longitudinal elasticity (up to $325 \mathrm{GPa}$ ) and high creep resistance. Like other MAX phases, $\mathrm{Ti}_{3} \mathrm{SiC}_{2}$ also exhibits high impact strength, the ability to dampen vibrations (Ref 3 ) and an increased capability to absorb energy, especially in cyclic loading processes.

It is predicted that due to its low density and high mechanical strength parameters, $\mathrm{Ti}_{3} \mathrm{SiC}_{2}$ and its composites may replace nickel-based superalloys for the construction of engine components. Being a good thermal conductor with a low coefficient of thermal expansion, it is also a promising alternative to materials commonly used for working at high temperatures, such as bushings, brake disks and heat exchangers (Ref 4).

$\mathrm{Ti}_{3} \mathrm{SiC}_{2}$-based materials are commonly manufactured using one of the following methods (Ref 3, 5-7): Hot Pressing (HP, RHP, HIP), Self-propagating High-temperature Synthesis (SHS), in-situ, Spark Plasma Sintering (SPS), Vacuum, Discharge or Pressureless Sintering (VS, PDS, PS), Mechanical Alloying (MA), Chemical Vapor Deposition (CVD) and 3D printing. Some of these techniques can also be applied for the fabrication of MAX phase-based composite materials.

However, in the case of SHS products, which are usually highly porous, additional pressure or pressureless infiltration is necessary for the creation of a dense composite material. Infiltration methods have until now been generally reserved for $\mathrm{Ti}_{2} \mathrm{AlC}$ - or $\mathrm{Ti}_{3} \mathrm{AlC}_{2}$-based composite materials (Ref 8, 9). In studies using these, it is reported that residual porosity was one of the most crucial problems. To overcome this issue, squeeze casting infiltration has been proposed as an alternative to conventionally used techniques, as this method ensures the most precise filling of open pores of the preform and highquality bonding of the reinforcement alloy. This method was previously used by the authors to produce $\mathrm{Al}-\mathrm{Si}$ matrix composite materials reinforced with MAX phases from a TiAl-C system (Ref 10).

The present study aims to develop a new beneficial method, including the synthesis of $\mathrm{Ti}_{3} \mathrm{SiC}_{2}$ MAX preforms and 
subsequent saturation with molten metal. SHS synthesis with correctly attuned parameters can provide a homogeneous porous structure quickly and effectively. With subsequent high-pressure infiltration, these fine structures can be completely saturated, thus reinforcing the Al alloy casting. By performing examinations of microstructure and basic physical properties, it is possible to select the optimized process parameters and confirm the benefits of this method.

\section{Materials and Methods}

Commercial powders of $\mathrm{Ti}(99.5 \% \mathrm{Ti},-325 \mathrm{mesh}$, Alfa Aesar), SiC (99.9\% SiC, -325 mesh, Alfa Aesar) and graphite (99.5\% C, - 325 mesh, SGL Carbon Ltd.) were used as starting materials in the molar ratios 3:1.2:1 to prepare a stoichiometric reactant mixture for the fabrication of $\mathrm{Ti}_{3} \mathrm{SiC}_{2}$. First, the $\mathrm{Ti}, \mathrm{SiC}$ and $\mathrm{C}$ powders were mixed with balls of $\mathrm{ZrO}_{2}$ for $10-30 \mathrm{~min}$, or for 3-14 $\mathrm{h}$ in the case of mechanical activation, with a ballto-powder ratio (BPR) of 10:1. Subsequently, the powders were uniaxially cold-pressed under a pressure of 450-930 $\mathrm{MPa}$ for $60 \mathrm{~s}$, to form cylindrical samples in the shape of pellets with $22 \mathrm{~mm}$ diameter, $4 \mathrm{~mm}$ of height and mass of $4 \mathrm{~g}$. The prepared samples were subjected to a MASHS process. The glass reaction chamber was filled with alumina fibers, transparent to microwaves, to provide conditions that are nearly adiabatic and to protect the reaction chamber from the effects of extreme temperature. As the $\mathrm{Ti} / \mathrm{SiC} / \mathrm{C}$ combination has a high ignition temperature, additional padding is required. In this technique, called coupled MASHS (Ref 11, 12), the 3Ti1.2SiC-C compact was placed onto a $2 \mathrm{Ti}-\mathrm{Al}-\mathrm{C}$ compact, the role of which is to boost the reaction above the ignition temperature of the substrates. Microwave magnetron power was applied in the range $300-400 \mathrm{~W}$. The whole reaction took place under the flow of an Ar atmosphere. The temperature was controlled by a Raytek Marathon MM pyrometer with a measuring spot diameter of $0.6 \mathrm{~mm}$. Further processing details are as presented elsewhere for Ti-Al-C systems (Ref 13).

The prepared MAX skeletons were subsequently used for pressure infiltration: squeeze casting with an Al-Si eutectic alloy, AC $44200(10-13.5 \% \mathrm{Si}, 0.4 \% \mathrm{Fe}, 0.05 \% \mathrm{Cu}, 0.4 \% \mathrm{Mn}$, $0.1 \% \mathrm{Zn}, 0.15 \% \mathrm{Ti}$, remainder $\mathrm{Al})$. The molten metal $\left(740{ }^{\circ} \mathrm{C}\right)$ was applied under pressure $(90 \mathrm{MPa})$ to the ceramic skeleton, preheated to $750{ }^{\circ} \mathrm{C}$, for $2 \mathrm{~min}$. The resulting composite was analyzed using a Hitachi S-3400 N scanning microscope, a SwiftED3000 chemical analyzer and an Ultima IV x-ray diffractometer $(40 \mathrm{kV} / 40 \mathrm{~mA}$, step 0.04$)$. TEM observation of the samples, ground to a thickness of $5 \mu \mathrm{m}$ with a Gatan Dimple Grinder and Gatan DuoMil ion polisher, was performed with a Hitachi H-800 transmission microscope $(150 \mathrm{kV})$. The samples were also analyzed by transmission analytical electron microscopy in scanning mode (STEM) with a convergent beam, using a JEOL 2100 electron microscope operating at 200 $\mathrm{kV}$ and equipped with a JEOL JED-2300T EDS unit for analytical measurements.

Thermal diffusivity and specific heat were measured using an LFA457/Netzsch laser flash analyzer and an STA 449 F1 Jupiter Netzsch device, respectively. The thermal expansion coefficients were determined using a DIL 402 Netzsch dilatometer. All measurements were carried out under a protective atmosphere of argon.
Mechanical properties, such as instrumental hardness and Young's modulus, were established with an NHT (Anton Paar) nanoindenter using the Oliver-Pharr method (Ref 14). Indentations were performed with a diamond Berkovich-type indenter for linear loading with a maximum load of $50 \mathrm{mN}$. Loading and unloading rates were both $100 \mathrm{mN} / \mathrm{min}$.

\section{Results and Discussion}

\subsection{Microwave-Assisted Self-Propagating High-Temperature Synthesis}

The fabrication of an open-porous structure of a MAX preform, with sufficient conversion of the substrates and the strength required for pressure infiltration, involves the determination of parameters for the MASHS synthesis. Powders, with a suitable stoichiometric ratio, were mixed for 10-30 min to obtain a homogeneous mixture or were ball-milled for 3-14 h to achieve better contact between the particles and to activate them. The green mixture was uniaxially cold-pressed under a pressure of $450-930 \mathrm{MPa}$, creating the initial porosity and conditions needed for the self-propagation reaction. Examples of the curves obtained from the samples produced from the green compact mixed and compressed under $930 \mathrm{MPa}$, and from further samples subjected to mechanical activation in a ball mill (3 hours, BPR 10:1, $\mathrm{ZrO}_{2}$ balls) instead of regular mixing, are presented in Fig. 1. The graph shows that mechanical activation decreases the combustion temperature significantly. However, mechanical activation of the powders caused the resulting preform to be less porous, contrary to the aim of the experiment. Therefore, the conditions selected for further experiments consisted of basic mixing and a relatively high compaction pressure. During pressing, only the $\mathrm{Ti}$ particles were plastically deformed, and their oxide films were disrupted. Moreover, the particle interlocking necessary to produce a tough compact was diminished by the carbon, which acts as a kind of solid lubricant. $\mathrm{SiC}$ was chosen as the source of $\mathrm{Si}$ in the Ti-Si-C combination, because in previous studies it was found advantageous for the production of $\mathrm{Ti}_{3} \mathrm{SiC}_{2}$ with high purity (Ref 2). Nevertheless, as $\mathrm{SiC}$ particles are far less reactive than the $\mathrm{Al}$ or $\mathrm{TiC}$ phases, for example, that are present in the Ti-Al-C combination, it is necessary to apply coupled MASHS synthesis. Merzhanov et al. have reported multiple studies of this particular mode of combustion synthesis (Ref 11, 12). To compensate for the evaporation of Si during MASHS synthesis, excess $\mathrm{Si}$ was added by altering the molar ratio of the initial mixture to $\mathrm{Ti} / \mathrm{SiC} / \mathrm{C}=3: 1.2: 1$. This composition has also been used for SHS synthesis by Saed et al., who found that it led to the highest $\mathrm{Ti}_{3} \mathrm{SiC}_{2}$ content in the synthesized material (Ref 4). The synthesis begins after around $10-15 \mathrm{~s}$ of microwave heating. The first peak visible on the curve for the Ti-Si-C combination represents the energy impact from the TiAl-C sample (the coupled SHS technique) in which the SHS reaction occurs earliest.

With the addition of SiC particles, the synthesis proceeds along a slightly different course than for the elementary powders and free silicon. The first observed temperature fluctuation, especially with the mixture mechanically activated (Fig. 1, point A), corresponds to the allotropic transformation $\mathrm{Ti}(\alpha) \rightarrow \operatorname{Ti}(\beta)$ at $882^{\circ} \mathrm{C}$. The more reactive $\beta$ phase (Ref 15$)$ triggers a synthesis by forming titanium carbide, $\operatorname{Ti}(\beta)+\mathrm{C}$ 


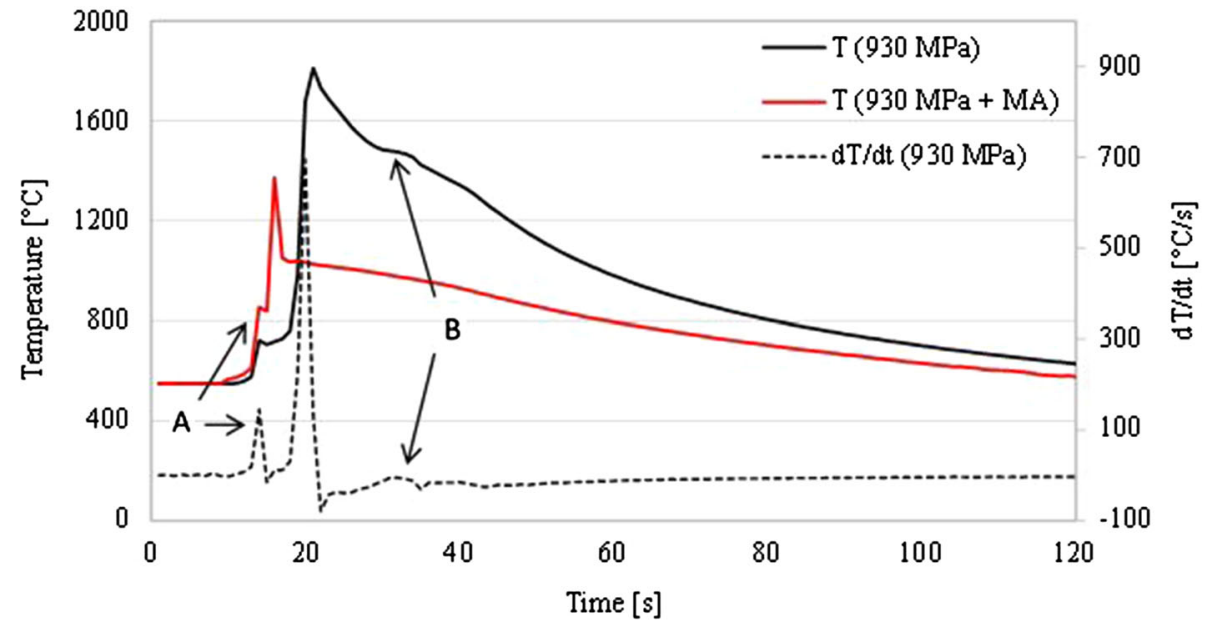

Fig. 1 Temperature-time dependences and derivative thermal analysis $(\mathrm{d} T / \mathrm{d} t)$ of SHS synthesis for powders compacted under $930 \mathrm{MPa}$ : mixed only (930 MPa) and mechanically activated (930 MPa + MA)

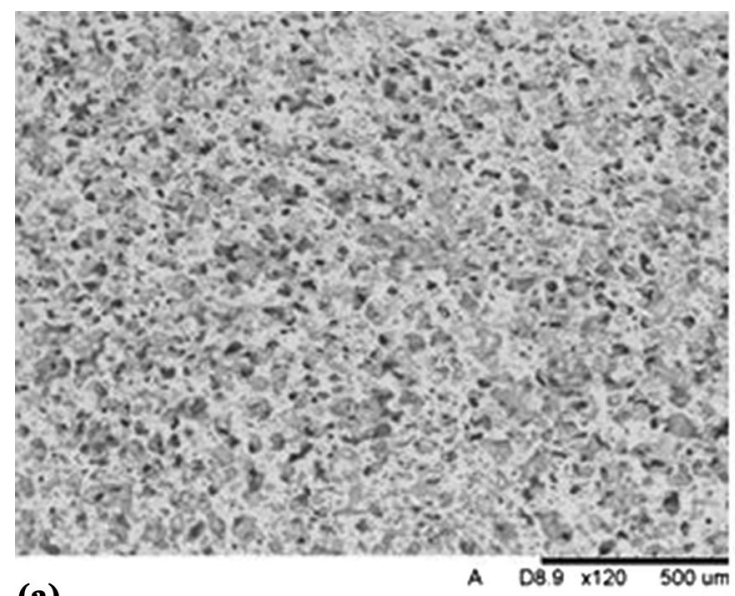

(a)

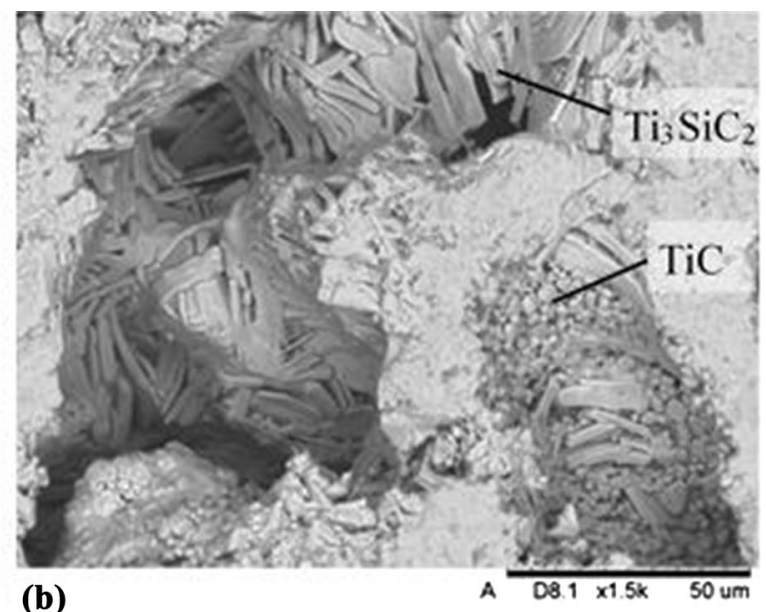

(b)

Fig. 2 Overall open porosity of manufactured material after $\mathrm{SHS}$ synthesis (a); $\mathrm{Ti}_{3} \mathrm{SiC}_{2}$ plates with round inclusions of $\mathrm{TiC}$ (b)

$\rightarrow \mathrm{TiC}_{\mathrm{x}}$, thereby providing the initial energy to make the reaction self-sustaining. Until all of the free $\mathrm{C}$ is consumed, the temperature must increase to a sufficient level. At that point, Ti reacts with $\mathrm{SiC}$, releasing the $\mathrm{Si}$. In Ref 15, 16, it is suggested that the reaction proceeds by diffusion and only small quantities of liquid are formed, possibly at the interface. The TEM observations presented below confirm the presence of $\mathrm{TiSi}_{2}$ crystals, which can be formed directly from the melt at $1478{ }^{\circ} \mathrm{C}$, at much lower temperatures than detected in the synthesis. Moreover, the $\mathrm{Si}$ released interferes with the $\mathrm{TiC}$ produced by the intermediate phase, which can be defined as a solid solution of $\mathrm{Si}$ in $\mathrm{TiC}$. The final product of the $\mathrm{Ti}_{3} \mathrm{SiC}_{2}$ MAX phase does not grow directly from SHS synthesis; rather, it precipitates from the converted intermediate phase. As an exothermic process, it confirms, based on the deviation observed on the cooling curve (point B), the minimum temperature $\left(1450^{\circ} \mathrm{C}\right)$ for successful sintering (Ref 15).

\subsection{Microstructure}

The process parameters selected should lead to preforms with a structure that is appropriate for metal infiltration. Figure 2(a) presents the overall open porosity of the resulting material, with good homogeneity and regular pore dimensions. The $\mathrm{Ti}_{3} \mathrm{SiC}_{2}$ phases typically appear as elongated plate grains, connected together in packets $10-20 \mu \mathrm{m}$ in length and 1-3 $\mu \mathrm{m}$ in thickness (Fig. 2b). The surfaces of pore walls formed from MAX plates are often covered with characteristic round TiC inclusions. The presence of hard carbides leads to high resistance to brittle fracture, because such particles can block the propagation of cracks within the material (Ref 17).

The microstructure of Al-Si eutectic alloy AC 44200 is shown in Fig. 3. After infiltration, the composites underwent repeated SEM, EDS, XRD and TEM/STEM analyses. The identification of particular phases by EDS analysis is presented in Fig. 4. $\mathrm{TiSi}_{2}$ phase was at first not detected during EDS analysis. Its formation was further confirmed with TEM and STEM analyses. Figure 5(a) shows the microstructure of the Al-Si composite reinforced by the MAX skeleton. Pores with an average size of $50 \mu \mathrm{m}$ are filled with the Al alloy, which during the final stages of infiltration penetrates even the walls created by the MAX plates. The scattered black spots represent remnants of partly reacted $\mathrm{SiC}$ particles. Residual porosity, which amounts to several percent, is located in places where $\mathrm{C}$ flakes are present. It is likely that external layers of the large particles reacted during synthesis with the remaining $\mathrm{TiC}$ and 


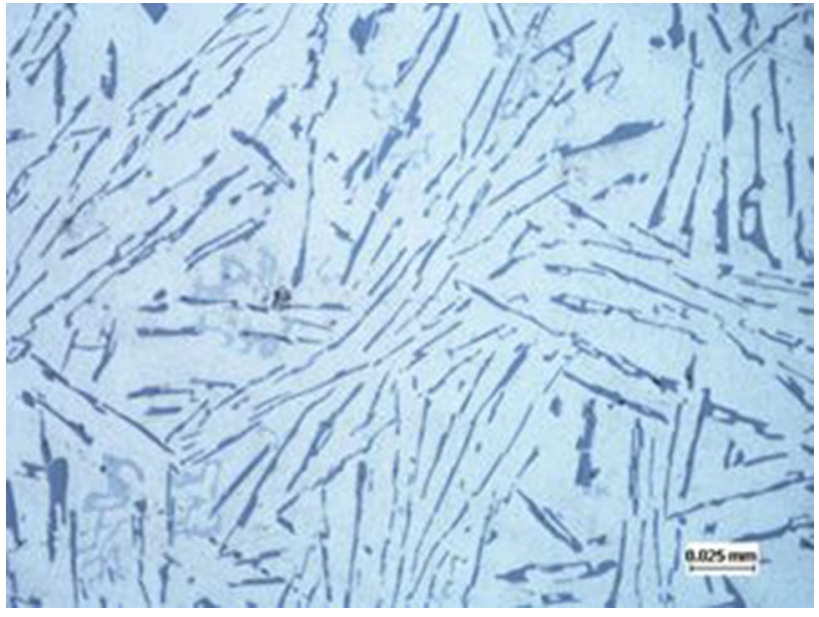

Fig. 3 Microstructure of Al-Si eutectic alloy AC 44200

limited amounts of $\mathrm{Ti}$ converted into closed gas pores. As a very high-pressure process, squeeze casting can force the liquid to break the thin walls of closed pores and fill the preform almost completely. MAX plates are often bonded with a thin layer of $\mathrm{TiSi}_{2}$ phase (Fig. 5b). Such stacks formed with narrow gaps between the plates are also effectively saturated with the alloy. Despite extension of the time for which the applied pressure was maintained, to improve the overall filling, no further reaction took place between the $\mathrm{Ti}_{3} \mathrm{SiC}_{2}$ preform and the Al-Si matrix. The volumetric ratio of alloy to reinforcement was maintained at about 40:60. Moreover, it can be stated that the Al-Si alloy can be actually improved by squeeze casting, because of its microstructure refinement (Ref 18, 19).

\subsection{XRD Analysis}

The XRD spectra acquired from the material after MASHS synthesis showed the presence of the main MAX phase of $\mathrm{Ti}_{3} \mathrm{SiC}_{2}$ and minor amounts of $\mathrm{TiC}_{\mathrm{x}}, \mathrm{TiSi}_{2}$ and $\mathrm{SiC}$ (Fig. 6). A quantitative Rietveld analysis of the manufactured preforms revealed the following constituents: $\mathrm{Ti}_{3} \mathrm{SiC}_{2} 75.90$ wt.\%, $\mathrm{TiC}$ 14.71 wt. $\%$, $\mathrm{TiSi}_{2} 8.27$ wt.\%, $\mathrm{SiC} 1.12$ wt.\%. To eliminate the remaining $\mathrm{SiC}$ phase, it may be advantageous to limit the amount of $\mathrm{SiC}$ in the substrate composition. Unlike in other studies (Ref 5), no $\mathrm{Ti}_{5} \mathrm{Si}_{3}$ inclusions were found in the synthesized material. Based on the ratio of the heights of individual reflections and the absence of reflection of the crystal lattice at an angle of $2 \theta=46^{\circ}$, the material synthesised from the Ti-Si-C combination is found to be $\alpha-\mathrm{Ti}_{3} \mathrm{SiC}_{2}$ (Ref 20).

On examination of the composite comprising the preform infiltrated with $\mathrm{Al}$ alloy, it was found that the additional reflections that appeared in the spectra, compared with the previously tested preforms, come only from the matrix material: $\mathrm{Al}$ or $\mathrm{Si}$. This indicates the absence of chemical reactions after the infiltration process. In addition, the tests do not show differences between the alloy material within the composite and the reference sample. In the alloy filling the interior pores of the preform, no element diffusion of the reinforcement material was found.

\subsection{TEM Characterization}

A plate-type $\mathrm{Ti}_{3} \mathrm{SiC}_{2}$ grain was detected using a selected area diffraction pattern and the sampling planes (001) $\left(d_{001}=1.767 \mathrm{~nm}\right), \quad(010) \quad\left(d_{010}=0.266 \mathrm{~nm}\right) \quad$ and $\quad(011)$ $\left(d_{011}=0.263 \mathrm{~nm}\right)$; see Fig. 7. The main axis of the grain is parallel to the plane (010). Using the dark-field method, a 1$\mu \mathrm{m}$-wide precipitation inside the MAX phase was observed, and this was identified as a $\mathrm{TiC}$ phase (Fig. 7c, d). The $\mathrm{TiC}$ phase is slip-free, but the density of dislocations inside it is higher than in a MAX grain. The lower thermal expansion of TiC compared with its surrounding MAX phases results in the generation of tensile stresses in these precipitations. TEM observations of $\mathrm{Ti}_{3} \mathrm{SiC}_{2}$-based ceramics reported by Morgiel et al. (Ref 21) revealed a high density of dislocations and a large number of cracks at the $\mathrm{Ti}_{3} \mathrm{SiC}_{2} / \mathrm{TiC}$ interface. In the present study, most $\mathrm{TiC}$ particles were found to be located on the walls of pores, and no cracks were detected.

The presence of a $\mathrm{TiSi}_{2}$ intermetallic phase was detected using the sampling planes $(220)\left(d_{220}=0.207 \mathrm{~nm}\right)$ and $(130)$ $\left(d_{130}=0.156 \mathrm{~nm}\right)$; see Fig. 8 . The phase has a plate-like shape (Fig. 8a) and exhibits the effect of internal stress fields and dislocations in the Al matrix. As previously mentioned, a thermal mismatch produces stresses between the MAX preform components. Additionally, during solidification, the Al matrix - with a coefficient of thermal expansion more than twice as large-shrinks significantly and places the preform under compression.

Figure 9 presents an STEM image of the composite with the distribution of $\mathrm{C}, \mathrm{Al}, \mathrm{Si}$ and $\mathrm{Ti}$ elements. MAX phase platelets containing $\mathrm{Ti}, \mathrm{Si}$ and $\mathrm{C}$ were identified as included in a matrix of $\mathrm{Al}$ and $\mathrm{Si}$ crystallites with sizes up to $1 \mu \mathrm{m}$. Squeeze casting infiltration is a very fast process and lasts for about 1-2 s. At the end of this stage, the pressure increases abruptly to $90 \mathrm{MPa}$, pushing the liquid metal into small, nanoscale gaps. Contact with the reinforcement during solidification can be prolonged for tens of seconds, depending on the volume of the casting and heat transfer to the die. In the case of the samples produced here, solidification was calculated to last about $20 \mathrm{~s}$, and for this period, pressure was exerted on the casting. Under these favorable conditions, chemical interaction was restricted and no element transfer or formation of products at the interface was detected. It was shown in a previous study of the interfacial reaction between $\mathrm{Ti}_{3} \mathrm{SiC}_{2}$ particles and an $\mathrm{Al}$ matrix (Ref 22) that when kept at a temperature of $600{ }^{\circ} \mathrm{C}$ for as long as 10 hours the $\mathrm{Si}$ atoms from the MAX phase can enter the Al matrix and form an $\mathrm{Al}(\mathrm{Si})$ solution. Degradation of the MAX phase needs a higher temperature $\left(700{ }^{\circ} \mathrm{C}\right)$ to be maintained for a long time. It is not ruled out that in the present investigations some Si may have entered the Al-Si matrix at the interface, but this effect is negligible for the silumin group of alloys.

\subsection{Mechanical and Thermal Properties}

Mechanical testing involved measurements of hardness (HV) and instrumental modulus of longitudinal elasticity (EIT). The results obtained for the preforms and for the composite materials, in comparison with the matrix parameters, are summarized in Table 1. MAX-type phases are less hard than most ceramic materials, but harder than the majority of metals. Due to the nanolaminated structure of MAX phases, the result of a measurement depends to a great extent on its location. The hardness inside one of the MAX phase platelets can be significantly higher than the hardness measured in a larger area (Ref 23). The hardness values determined for preforms are close to the upper limit of the range reported previously by other researchers. In Ref 24 , dense polycrys- 


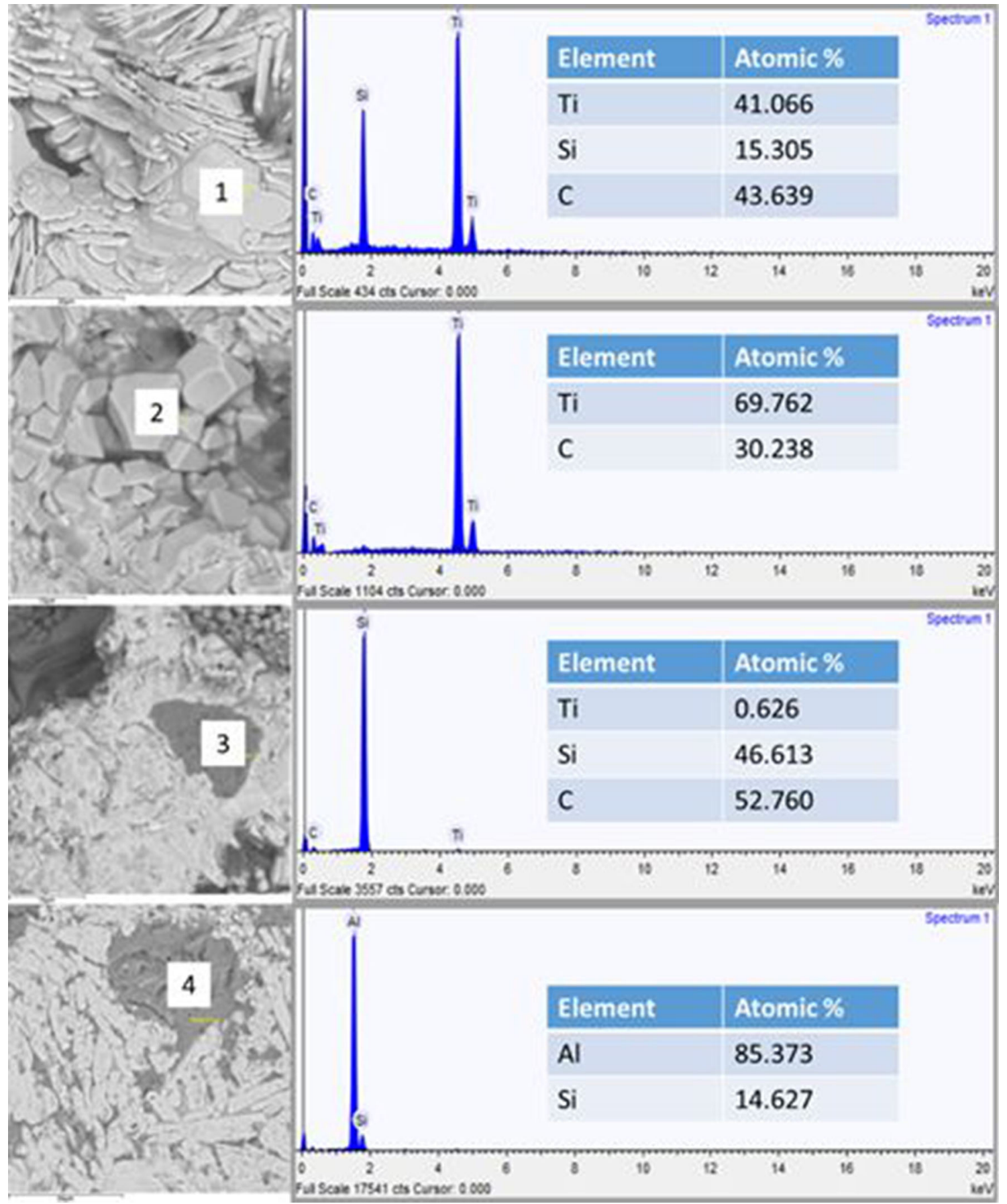

Fig. 4 Identification of particular phases by $\mathrm{EDS}$ analysis $\left(1-\mathrm{Ti}_{3} \mathrm{SiC}_{2} \mathrm{MAX}\right.$ phase platelets, 2- $\mathrm{TiC}$ inclusion, 3- $\mathrm{SiC}$ inclusion, 4- $\mathrm{Al}-\mathrm{Si}$ matrix after squeeze casting infiltration)

talline $\mathrm{Ti}_{3} \mathrm{SiC}_{2}$ of high purity, fabricated by reactive hot isostatic pressing, was found to have a hardness of only $4.0 \pm 0.2 \mathrm{GPa}$. Reinforcing $\mathrm{TiSi}_{2}-\mathrm{Ti}_{3} \mathrm{SiC}_{2}$ with nanoparticles of $\mathrm{SiC}$ improves the hardness to 11-12 GPa (Ref 25), which is only slightly higher than that of the porous preform presented here. Compared with the alloy, the fabricated composite material had a hardness more than five times greater and a Young's modulus almost six times greater. During solidification, the solid preform induces heterogeneous nucleation and refining of the matrix structure. Moreover, a relatively high volume of the preform results in a considerable reduction in released energy, due to the smaller fraction of liquid and latent heat. Thus, the composite solidified faster, and it was concluded that solid solution strengthening and precipitation strengthening (Si crystallites) both lead to an improvement in mechanical properties.

MAX phases have a higher coefficient of thermal conductivity $(\lambda)$ than binary $\mathrm{MX}$ or MA compounds. At room temperature, it lies in the range $12-60 \mathrm{~W} / \mathrm{m}{ }^{\circ} \mathrm{C}$, while the thermal expansion coefficient is approximately 5$11 \times 10^{-6}{ }^{\circ} \mathrm{C}^{-1}$ (Ref 26). The high thermal conductivity of MAX phases, according to the Wiedmann-Franz law, is 


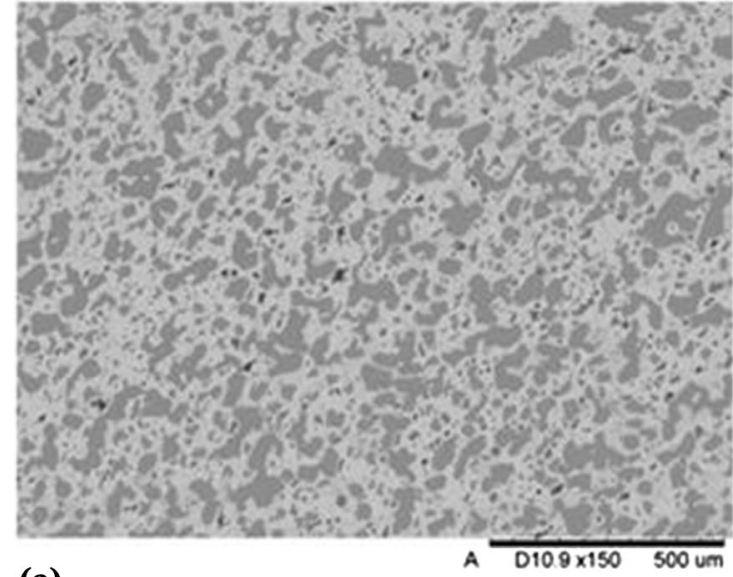

(a)

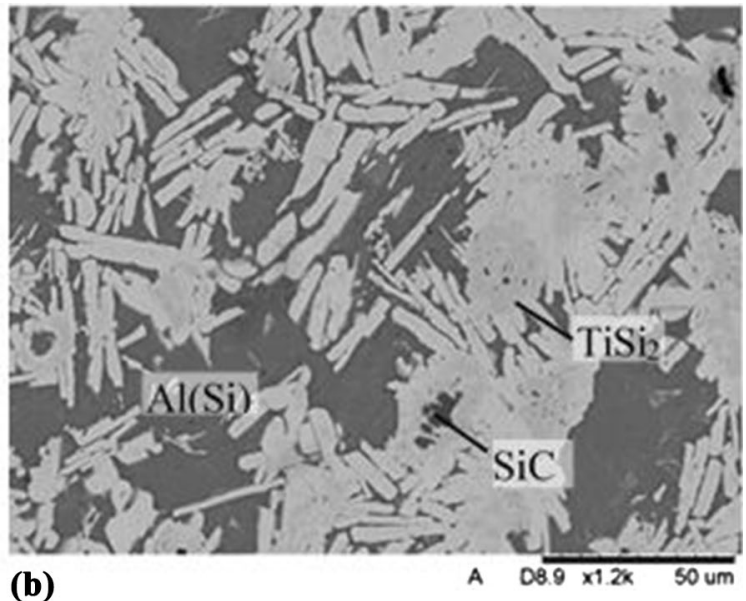

(b)

Fig. 5 Microstructure of the Ti-Si-C MAX/Al-Si composite material: overall view (a); $\mathrm{SiC}$ inclusions and $\mathrm{Ti}_{3} \mathrm{SiC}_{2}$ plates bonded with $\mathrm{TiSi}_{2}$ layers (b)

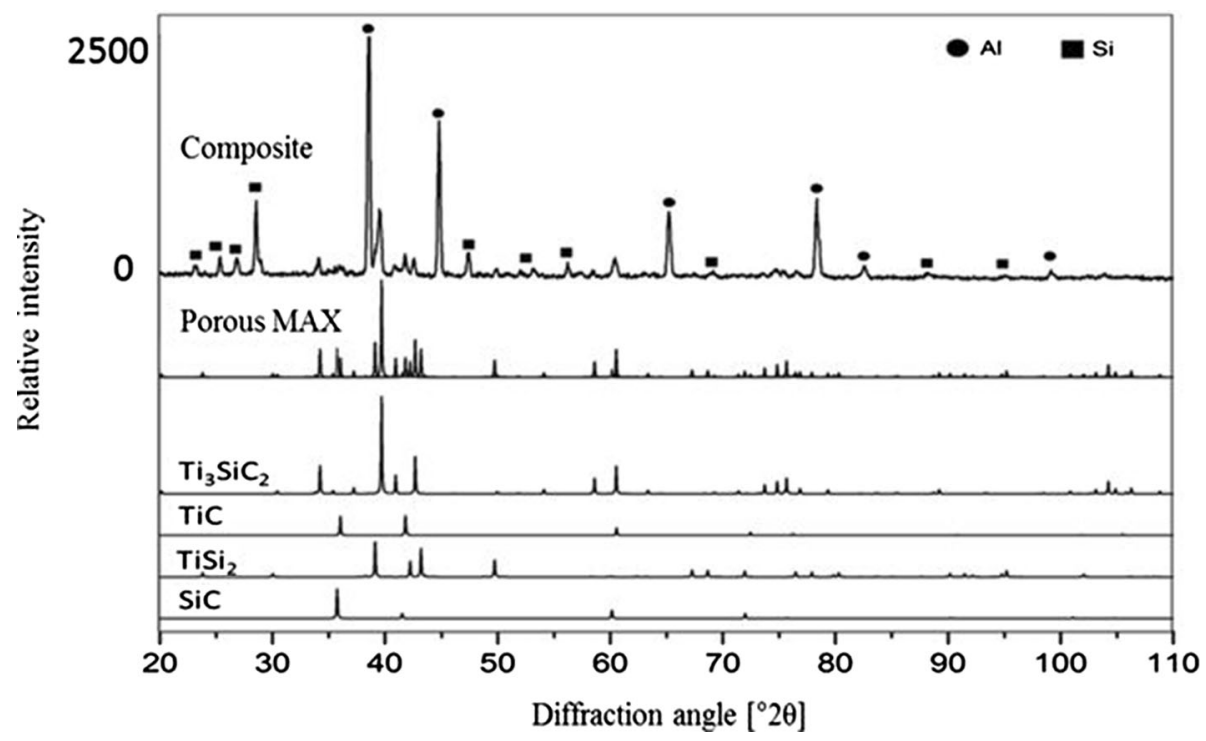

Fig. 6 XRD patterns for samples before and after the squeeze casting pressure infiltration process

directly related to their good electrical conductivity. The overall coefficient of thermal conductivity of a material is the sum of phonon and electron thermal conductivity (Ref 27). MAX phase materials containing Si mainly owe their overall thermal conductivity to electron thermal conductivity (Ref 26). At room temperature, the electron thermal conductivity of $\mathrm{Ti}_{3} \mathrm{SiC}_{2}$ is $33 \mathrm{~W} / \mathrm{m}{ }^{\circ} \mathrm{C}$, while its phonon thermal conductivity is $1 \mathrm{~W} /$ $\mathrm{m}{ }^{\circ} \mathrm{C}$; these combine to give a theoretical overall thermal conductivity of $34 \mathrm{~W} / \mathrm{m}^{\circ} \mathrm{C}(\operatorname{Ref} 23)$. For the majority of MAX phases, apart from $\mathrm{Ti}_{4} \mathrm{AlN}_{3}, \mathrm{Nb}_{2} \mathrm{AlC}$ and $\mathrm{Ta}_{4} \mathrm{AlC}_{3}$, the thermal conductivity decreases slightly with an increase in temperature (Ref 23); this was also observed in the present study. Table 2 summarizes the thermal properties obtained for materials fabricated in the temperature range $50-500{ }^{\circ} \mathrm{C}$. As temperature increased, with the effects of lattice distortion, molecule vibration and the obstructed flow of free electrons, thermal diffusivity decreased by about $25 \%$ in both the $\mathrm{Al}$ alloy and the composite. Specific heat increased with increasing temperature, as observed in previous studies (Ref 27).
Based on thermal diffusivity, density $(\rho)$ and specific heat $\left(c_{\mathrm{p}}\right)$, the thermal conductivity $(\lambda)$ was determined from the equation $\lambda=c_{\mathrm{p}} a \rho$. The change in mass, measured by thermogravimetric analysis (TGA), for the Al-Si alloy and $\mathrm{Al}-\mathrm{Si}+\mathrm{Ti}-\mathrm{Si}-\mathrm{C}$ composite was $0.35 \%$ and $0.13 \%$, respectively. Reinforcing the metal matrix involves the formation of new grain boundaries, pores or particles, which naturally reduce thermal conductivity. Conductivity is almost $60 \%$ lower in the composite than in the Al-Si alloy, but compared with the base $\mathrm{Ti}_{3} \mathrm{SiC}_{2}\left(34-37 \mathrm{~W} / \mathrm{m}^{\circ} \mathrm{C}\right)$ (Ref 28) a twofold improvement was observed.

The measured coefficients of thermal expansion confirm a more than twofold improvement in thermal dimensional stability for the fabricated $\mathrm{Al}-\mathrm{Si} / \mathrm{Ti}_{3} \mathrm{SiC}_{2}$ composite compared with the alloy material (Fig. 10). The thermal expansion of the $\mathrm{Al}-\mathrm{Si} / \mathrm{Ti}_{3} \mathrm{SiC}_{2}$ composite material is comparable to that of the reinforcing MAX phase. In the case of the Al-Si alloy, the expansion coefficient shows a slow upward tendency until around $250{ }^{\circ} \mathrm{C}$ and then decreases with further increase in 


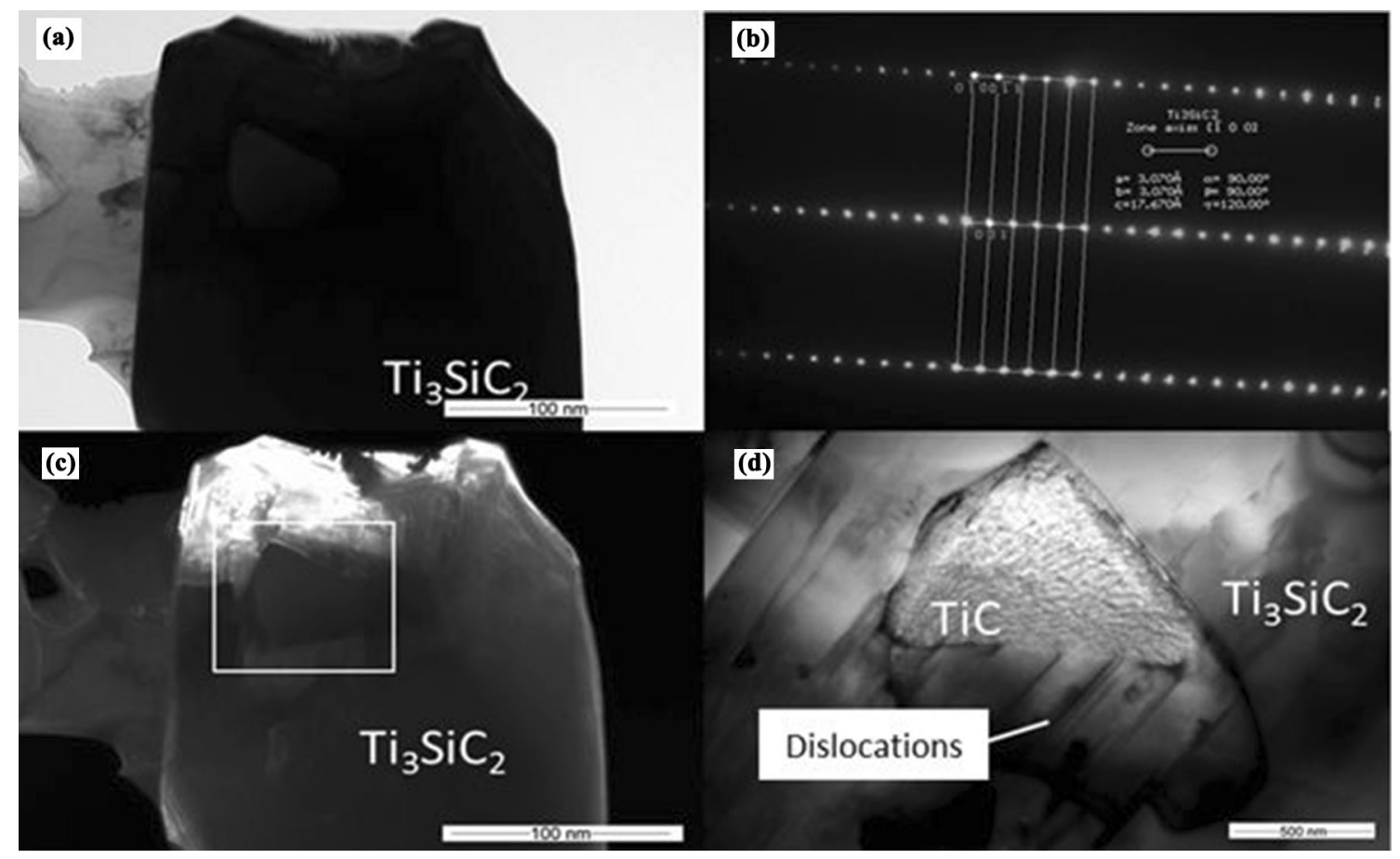

Fig. 7 TEM microstructure of $\mathrm{Ti}_{3} \mathrm{SiC}_{2}$ phase after infiltration: bright-field image of $\mathrm{Ti}_{3} \mathrm{SiC}_{2}$ plate (a); selected area diffraction pattern obtained in $\mathrm{Ti}_{3} \mathrm{SiC}_{2}$ (b); dark-field image of $\mathrm{Ti}_{3} \mathrm{SiC}_{2}$, taken in the (010) reflection, showing precipitation inside the MAX phase, marked with a square (c); bright-field image showing the TiC/MAX interface with (010) slip planes in the MAX phase (d)

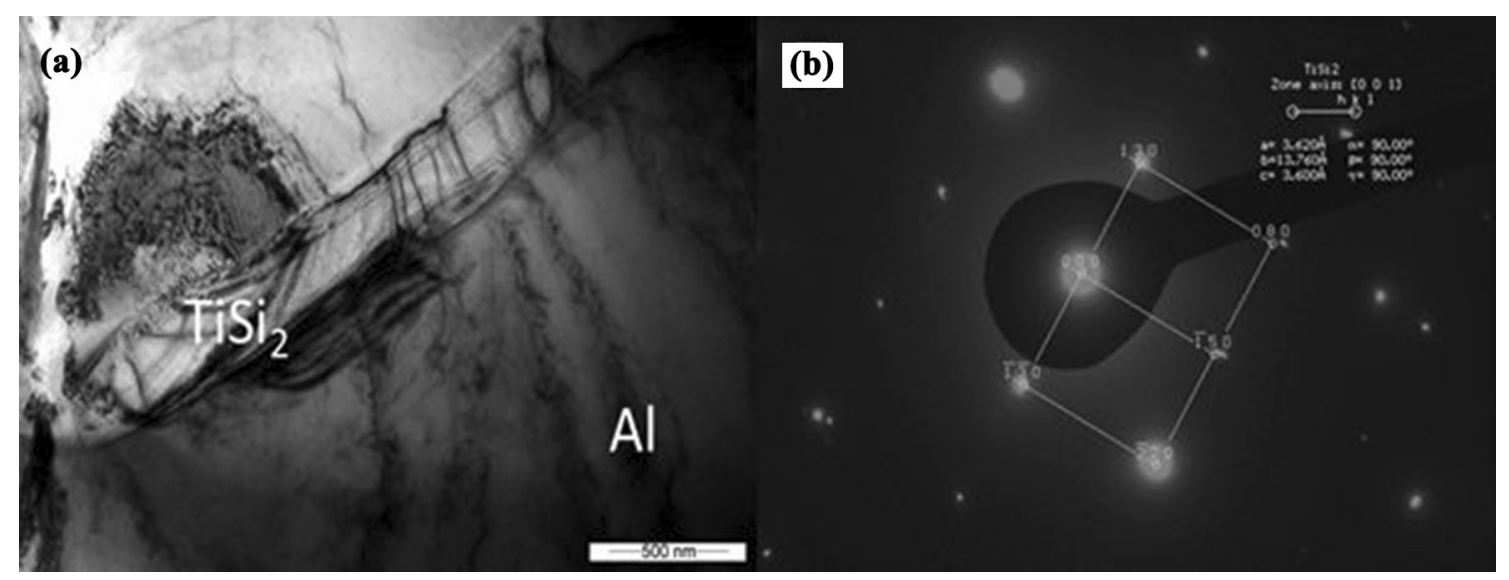

Fig. 8 Bright-field image of $\mathrm{TiSi}_{2}$ precipitation close to the $\mathrm{Al}$ matrix (a); selected area diffraction pattern obtained from the same place (b)

temperature. Similar peaks on the curve between $250{ }^{\circ} \mathrm{C}$ and $400{ }^{\circ} \mathrm{C}$, observed by Choi et al., were explained by precipitation of the Si phase. Squeeze casting with the use of a metal die proceeds with fast cooling and solidification; therefore, overcooling and saturation of $\mathrm{Al}$ with $\mathrm{Si}$ may occur. In this case, small Si crystallites were observed in the composite structures. However, the thermal expansion (8.5$10 \times 10^{-6}{ }^{\circ} \mathrm{C}^{-1}$ ) of the composite is almost constant as a function of temperature. That corresponds with the properties of pure MAX phases, which usually lie in the range 5$11 \times 10^{-6}{ }^{\circ} \mathrm{C}^{-1}(\operatorname{Ref} 27)$, as presented for the temperature range $25-1000{ }^{\circ} \mathrm{C}$ by Barsoum et al. (Ref 25) $\left(9.1 \times 10^{-6}{ }^{\circ} \mathrm{C}^{-1}\right)$ and Son et al. (Ref 29) (9.1$\left.11 \times 10^{-6}{ }^{\circ} \mathrm{C}^{-1}\right)$ and for commercial powders of $\mathrm{Ti}_{3} \mathrm{SiC}_{2}$ (Ref 30) $\left(7-9 \times 10^{-6}{ }^{\circ} \mathrm{C}^{-1}\right)$. It may be assumed that the $\mathrm{Ti}_{3} \mathrm{SiC}_{2}$ skeleton restrains thermal expansion of the matrix, especially at higher temperatures when the Al-Si alloy is more plastic. The yield strength of the alloy quickly decreases above $200{ }^{\circ} \mathrm{C}$ (Ref 31$)$ and the compression stress generated by the skeleton results in less overall expansion.

\section{Summary and Conclusions}

A novel method for manufacturing Al metal matrix composites based on a Ti-Si-C MAX phase has been successfully developed by combining two techniques: MicrowaveAssisted Self-propagating High-temperature Synthesis (MASHS) and squeeze casting infiltration. Both of these methods were modified in order to achieve an open-porous structure and subsequently enable the full infiltration of 

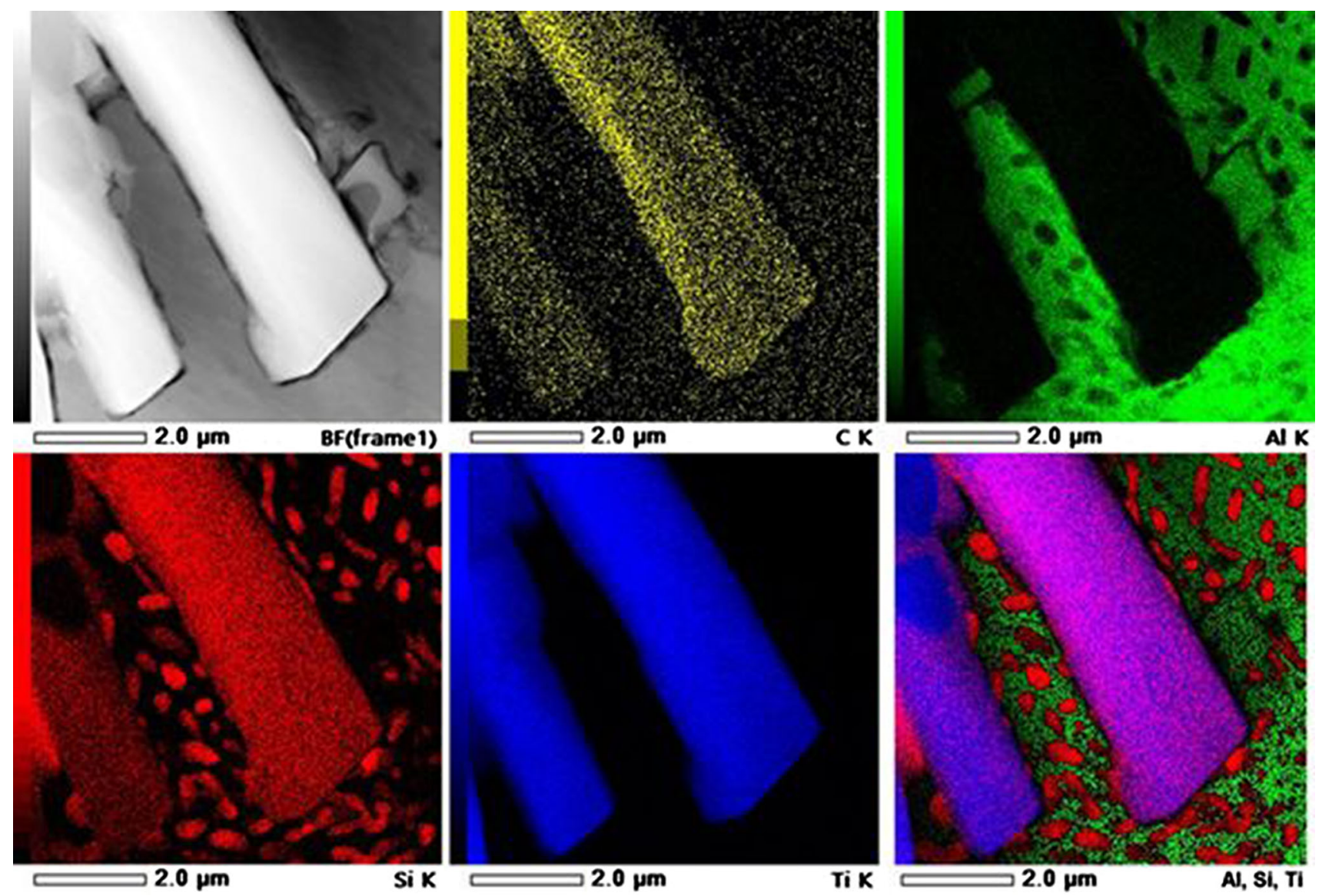

Fig. 9 STEM image and corresponding EDS maps showing the distribution of $\mathrm{C}, \mathrm{Al}, \mathrm{Si}$ and $\mathrm{Ti}$ in the analyzed area. The RGB image was obtained by superimposing the EDS maps of $\mathrm{Al}, \mathrm{Si}$ and $\mathrm{Ti}$

Table 1 Mechanical properties of the manufactured materials

\begin{tabular}{lcc}
\hline $\begin{array}{l}\text { Property } \\
\text { Material }\end{array}$ & Hardness $(\mathbf{H V}), \mathbf{G P a}$ & Instrumental Young's modulus (EIT), GPa \\
\hline $\mathrm{EN} \mathrm{AC}-44200$ alloy & 1.6 & 29.0 \\
$\mathrm{Ti}_{3} \mathrm{SiC}_{2}$-preform & 10.8 & 257.6 \\
$\mathrm{Ti}_{3} \mathrm{SiC}_{2}$ - composite & 8.5 & 170.8 \\
\hline
\end{tabular}

Table 2 Thermal properties of the alloy and composite at $50-500{ }^{\circ} \mathrm{C}$

\begin{tabular}{|c|c|c|c|c|c|c|}
\hline \multirow[b]{2}{*}{$\begin{array}{l}\mathrm{T}, \\
{ }^{\circ} \mathrm{C}\end{array}$} & \multicolumn{3}{|c|}{ Al-Si alloy } & \multicolumn{3}{|c|}{$\mathrm{Al}-\mathrm{Si}+\mathrm{Ti}-\mathrm{Si}-\mathrm{C}$ composite } \\
\hline & $\begin{array}{l}\text { Thermal diffusivity, } \\
\qquad \mathrm{mm}^{2} \mathrm{~s}^{-1}\end{array}$ & $\begin{array}{l}\text { Thermal conductivity, } \\
\text { W/m }{ }^{\circ} \mathbf{C}\end{array}$ & 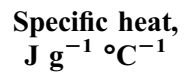 & $\begin{array}{l}\text { Thermal diffusivity, } \\
\qquad \mathrm{mm}^{2} \mathrm{~s}^{-1}\end{array}$ & $\begin{array}{c}\text { Thermal conductivity, } \\
\mathrm{W} / \mathrm{m}^{\circ} \mathrm{C}\end{array}$ & $\begin{array}{l}\text { Specific heat, } \\
\mathrm{J} \mathrm{g} \mathrm{g}^{-1}{ }^{\circ} \mathrm{C}^{-1}\end{array}$ \\
\hline 50 & $58.44 \pm 1.4$ & 177.7 & 0.724 & $24.56 \pm 0.13$ & 66.8 & 0.933 \\
\hline 100 & $54.48 \pm 0.69$ & 163.9 & 0.735 & $23.22 \pm 0.04$ & 63.4 & 0.924 \\
\hline 200 & $50.03 \pm 0.07$ & 153.7 & 0.765 & $21.22 \pm 0.05$ & 59.3 & 0.933 \\
\hline 300 & $46.49 \pm 0.32$ & 144.4 & 0.796 & $19.80 \pm 0.13$ & 57.2 & 0.953 \\
\hline 400 & $45.5 \pm 0.07$ & 145.8 & 0.822 & $19.20 \pm 0.09$ & 58.5 & 1.015 \\
\hline 500 & $43.49 \pm 0.19$ & 170.6 & 0.855 & $18.09 \pm 0.11$ & 62.5 & 1.186 \\
\hline
\end{tabular}

preforms with the liquid metal. Based on microscopic observations and the evaluation of physical properties, the following conclusions are drawn:
1. MASHS of MAX phases in the Ti-Si-C combination $\left(\mathrm{Ti}_{3}\right.$ $\left.\mathrm{SiC}_{2}\right)$ is accompanied by the formation of inclusions of $\mathrm{TiC}$ (14.71 wt.\%), $\mathrm{TiSi}_{2}$ (8.27 wt.\%) and $\mathrm{SiC}$ (1.12 wt.\%). 


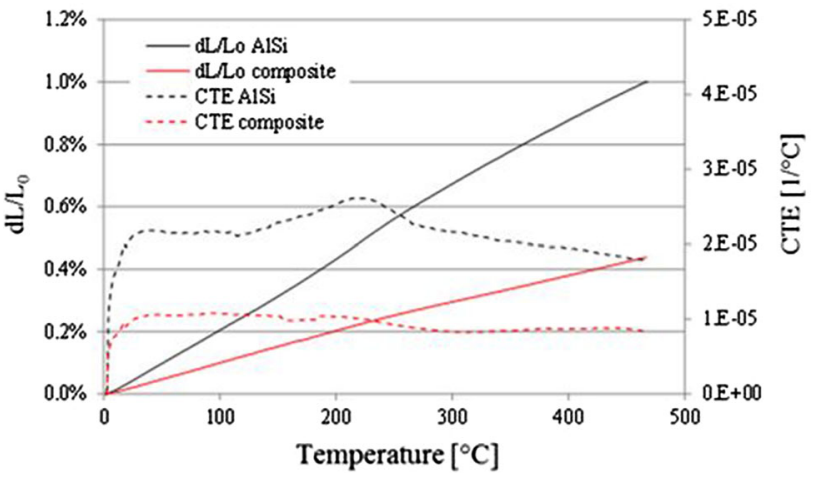

Fig. 10 The relative elongation $d L / L_{\mathrm{o}}$ and the coefficient of thermal expansion (CTE) of the matrix (AlSi) and $\mathrm{Al}-\mathrm{Si}+\mathrm{Ti}-\mathrm{Si}-\mathrm{C}$ (composite)

2. Squeeze casting pressure infiltration permits the complete filling of micro- and nanopores of the preform structure that is formed in plates.

3. As regards mechanical properties, the Vickers hardness and Young's modulus were five and six times higher, respectively, for the composite materials than for the reference Al-Si alloy.

4. The produced composite materials exhibit double the thermal conductivity of $\mathrm{Ti}_{3} \mathrm{SiC}_{2}$ and significantly increased thermal stability compared with the alloy. The coefficient of thermal expansion for the composite is half that of the Al-Si alloy.

\section{Acknowledgments}

The authors acknowledge the CERIC-ERIC Consortium for the access to experimental facilities and financial support. The authors would like to thank Ms. Agnieszka Baszczuk, who has performed the XRD measurements, for her support and assistance.

\section{Conflict of interest}

The authors declare that they have no conflict of interest.

\section{Open Access}

This article is distributed under the terms of the Creative Commons Attribution 4.0 International License (http://creativeco mmons.org/licenses/by/4.0/), which permits unrestricted use, distribution, and reproduction in any medium, provided you give appropriate credit to the original author(s) and the source, provide a link to the Creative Commons license, and indicate if changes were made.

\section{References}

1. E.H. Kisi, J.A.A. Crossley, S. Myhra, and M.W. Barsoum, Structure and Crystal Chemistry of $\mathrm{Ti}_{3} \mathrm{SiC}_{2}$, J. Phys. Chem. Solids, 1998, 59(9), p 1437-1443

2. C.L. Yeh and Y.G. Shen, Effects of $\mathrm{SiC}$ Addition on Formation of $\mathrm{Ti}_{3} \mathrm{SiC}_{2}$ by Self-Propagating High Temperature Synthesis, J. Alloys Compd., 2008, 461, p 654-660

3. M.A. El Saeed, F.A. Deorsola, and R.M. Rashad, Influence of SPS Parameters on the Density and Mechanical Properties of Sintered $\mathrm{Ti}_{3} \mathrm{SiC}_{2}$ Powders, Int. J. Refract. Met. Hard Mater., 2013, 41, p 48-53
4. M.A. El Saeed, F.A. Deorsola, and R.M. Rashad, Optimization of the $\mathrm{Ti}_{3} \mathrm{SiC}_{2}$ MAX Phase Synthesis, Int. J. Refract. Met. Hard Mater., 2012, 35, p 127-131

5. R. Radhakrishnan, J.J. Williams, and M. Akinc, Synthesis of HighTemperature Stability of $\mathrm{Ti}_{3} \mathrm{SiC}_{2}$, J. Alloys Compd., 1999, 285, p 8588

6. Y. Ma, X. Yin, X. Fan, and L. Wang, Near-Net-Shape Fabrication of $\mathrm{Ti}_{3} \mathrm{SiC}_{2}$-Based Ceramics by Three-Dimensional Printing, Int. J. Appl. Ceram. Technol., 2015, 12(1), p 71-80

7. B. Nan, X. Yin, L. Zhang, and L. Cheng, Three-Dimensional Printing of $\mathrm{Ti}_{3} \mathrm{SiC}_{2}$-Based Ceramics, J. Am. Ceram. Soc., 2011, 94(4), p 969972

8. B. Anasori, E. Caspi, and M. Barsoum, Fabrication and Mechanical Properties of Pressureless Melt Infiltrated Magnesium Alloy Composites Reinforced with $\mathrm{TiC}$ and $\mathrm{Ti}_{2} \mathrm{AlC}$ Particles, Mater. Sci. Eng., 2014, 618, p 511-522

9. B. Anasori and M. Barsoum, Energy Damping in Magnesium Alloy Composites Reinforced with $\mathrm{TiC}$ or $\mathrm{Ti}_{2} \mathrm{AlC}$ Particles, Mater. Sci. Eng., 2016, 653, p 53-62

10. A. Dmitruk, A. Żak, K. Naplocha, W. Dudziński, and J. Morgiel, Development of Pore-Free Ti-Al-C MAX/Al-Si MMC Composite Materials Manufactured by Squeeze Casting Infiltration, Mater. Char., 2018, 146, p 182-188

11. A.G. Merzhanov, Thermally Coupled SHS Reactions, Int. J. Self Propag. High Temp. Synth., 2011, 20(1), p 61-63

12. S.L. Kharatyan and A.G. Merzhanov, Coupled SHS Reactions as a Useful Tool for Synthesis of Materials: An Overview, Int. J. Self Propag. High Temp. Synth., 2012, 21(1), p 59-73

13. A. Dmitruk (Koniuszewska) and K. Naplocha, Microwave Assisted Self-propagating High-Temperature Synthesis of $\mathrm{Ti}_{2} \mathrm{AlC}$ Max Phase, Compos. Theory Pract., 2016, 16(2), p 109-112

14. G. Guillonneau, G. Kermouche, S. Bec, and J. Loubet, Determination of Mechanical Properties by Nanoindentation Independently of Indentation Depth Measurement, J. Mater. Res., 2012, 27, p 2551-2560

15. D.P. Riley, E.H. Kisi, T.C. Hansen, and A.W. Hewat, Self-propagating High-Temperature Synthesis of $\mathrm{Ti}_{3} \mathrm{SiC}_{2}$ : I, Ultra-high-Speed Neutron Diffraction Study of the Reaction Mechanism, J. Am. Ceram. Soc., 2002, 85(10), p 2417-2424

16. F. Goesmann, R. Wenzel, and R. Schmid-Fetzer, Preparation of $\mathrm{Ti}_{3} \mathrm{SiC}_{2}$ by Electron-Beam-Ignited Solid-State Reaction, J. Am. Ceram. Soc., 1998, 81(11), p 3025-3028

17. X. Chen and G. Bei, Toughening Mechanisms in Nanolayered MAX Phase Ceramics-A Review, Materials, 2017, 10, p 366

18. R.G. Guan, Z.Y. Zhao, Y.D. Li, T.J. Chen, S.X. Xu, and P.X. Qi, Microstructure and Properties of Squeeze Cast A356 Alloy Processed with a Vibrating Slope, J. Mater. Process. Technol., 2016, 229, p 514519

19. R. Li, L. Liu, L. Zhang, J. Sun, Y. Shi, and B. Yu, Effect of Squeeze Casting on Microstructure and Mechanical Properties of Hypereutectic Al-xSi Alloys, J. Mater. Sci. Technol., 2017, 33(4), p 404-410

20. C.L. Zhou, T.W.L. Ngai, L. Lu, and Y.Y. Li, Fabrication and Characterization of Pure Porous $\mathrm{Ti}_{3} \mathrm{SiC}_{2}$ with Controlled Porosity and Pore Features, Mater. Lett., 2014, 131, p 280-283

21. J. Morgiel, J. Lis, and R. Pampuch, Microstructure of $\mathrm{Ti}_{3} \mathrm{SiC}_{2}-$ Based Ceramic, J. Am. Ceram. Soc., 1998, 81(11), p 85-89

22. J. Zhang, W. Liu, Y. Jin, S. Wu, and X. Xiao, Study of the Interfacial Reaction Between $\mathrm{Ti}_{3} \mathrm{SiC}_{2}$ Particles and Al Matrix, J. Alloys Compd., 2018, 25, p 1-9

23. M.W. Barsoum and M.A.X. Phases, Properties of Machinable Ternary Carbides and Nitrides, Wiley-VCH, New York, 2013

24. N.F. Gao, Y. Miyamoto, and D. Zhang, On Physical and Thermochemical Properties of High-Purity $\mathrm{Ti}_{3} \mathrm{SiC}_{2}$, Mater. Lett., 2002, 55(12), p 61-66

25. C. Qin, L.J. Wang, W. Jiang, S.Q. Bai, and L.D. Chen, Microstructure Characterization and Mechanical Properties of $\mathrm{TiSi}_{2}-\mathrm{SiC}_{-} \mathrm{Ti}_{3} \mathrm{SiC}_{2}$ Composites Prepared by Spark Plasma Sintering, Mater. Trans., 2006, 47(3), p 845-848

26. M. Radovic, M. Barsoum, and M.A.X. Phases, Bridging the Gap Between Metals and Ceramics, Ceram. Soc. Bull., 2013, 92(3), p 20 27

27. Y. Bai, X. He, R. Wang, Y. Sun, C. Zhu, S. Wang, and G. Chen, High Temperature Physical and Mechanical Properties of Large-Scale $\mathrm{Ti}_{2} \mathrm{AlC}$ Bulk Synthesized by Self-propagating High-Temperature 
Combustion Synthesis with Pseudo Hot Isostatic Pressing, J. Eur Ceram. Soc., 2013, 33(13-14), p 2435-2445

28. M.W. Barsoum, T. El-Raghy, C.J. Rawn, W.D. Porter, H. Wang, E.A Payzant, and C.R. Hubbard, Thermal Properties of $\mathrm{Ti}_{3} \mathrm{SiC}_{2}, J$. Phys. Chem. Solids, 1999, 60, p 429-439

29. W. Son, T. Duong, A. Talapatra, H. Gao, R. Arroyave, and M. Radovic, $\mathrm{Ab}$-Initio Investigation of the Finite-Temperatures Structural, Elastic, and Thermodynamic Properties of $\mathrm{Ti}_{3} \mathrm{AlC}_{2}$ and $\mathrm{Ti}_{3} \mathrm{SiC}_{2}$, Comput. Mater. Sci., 2016, 124, p 420-427

30. C. Shih, R. Meisner, W. Porter, Y. Katoh, and S.J. Zinkle, Physical and Thermal Mechanical Characterization of Non-irradiated MAX Phase
Materials (Ti-Si-C and Ti-Al-C Systems), Fusion React. Mater. Program., 2013, 55, p 78-93

31. P. Zhang, Z. Li, B. Liu, and W. Ding, Tensile Properties and Deformation Behaviors of a New Aluminum Alloy for High Pressure Die Casting, J. Mater. Sci. Technol., 2017, 33(4), p 367-378

Publisher's Note Springer Nature remains neutral with regard to jurisdictional claims in published maps and institutional affiliations. 